https://helda.helsinki.fi

Dental functional morphology predicts the scaling of chewing rate in mammals

\title{
Zliobaite, Indre
}

2018-01-23

Zliobaite , I \& Fortelius , M 2018 , ' Dental functional morphology predicts the scaling of chewing rate in mammals ' , Journal of Biomechanics , vol. 67 , pp. 32-36 . https://doi.org/10.1016/j.jbiomech.2017.1

http://hdl.handle.net/10138/232703

https://doi.org/10.1016/j.jbiomech.2017.11.017

submittedVersion

Downloaded from Helda, University of Helsinki institutional repository.

This is an electronic reprint of the original article.

This reprint may differ from the original in pagination and typographic detail.

Please cite the original version. 


\title{
Dental functional morphology predicts the scaling of chewing rate in mammals
}

\author{
Indrè Žliobaitė*1,2 and Mikael Fortelius ${ }^{2,3}$ \\ 1 Dept. of Computer Science, University of Helsinki, Finland \\ 2 Dept. of Geosciences of Geography, University of Helsinki, Finland \\ 3 Finnish Museum of Natural History, University of Helsinki, Finland \\ *indre.zliobaite@helsinki.fi
}

\begin{abstract}
How food intake and mastication scale to satisfy the metabolic needs of mammals has been the subject of considerable scientific debate. Existing theory suggests that the negative allometric scaling of metabolic rate with body mass is compensated by a matching allometric scaling of the chewing rate. Why empirical studies have found that the scaling coefficients of the chewing rate seem to be systematically smaller than expected from theory remains unknown. Here we explain this imparity by decoupling the functional surface area of teeth from overall surface area. The functional surface area is relatively reduced in forms emphasizing linear edges (e.g., lophodont) compared with forms lacking linear structures (e.g., bunodont). In forms with reduced relative functional surface, the deficit in food processed per chew appears to be compensated for by increased chewing rate, such that the metabolic requirements are met. This compensation accounts for the apparent difference between theoretically predicted and observed scaling of chewing rates. We suggest that this reflects adaptive functional evolution to plant foods with different fracture properties and extend the theory to incorporate differences in functional morphology.
\end{abstract}

\section{Introduction}

A recent study in biophysiology by Virot et al. (2017) highlighted that scaling in mastication and processing of food does not strictly follow fixed laws, but balances between physical, physiological and temporal limits. Ever since the scaling of chewing rates was established for ungulates (Fortelius 1985), a lot of empirical evidence on chewing rates has been gathered to support or clarify the theory (Fortelius 1985, Druzinsky 1993, Shipley et al. 1994, Gerstner and Gernstein 2008, Ross et al. 2009, Ungar 2014, Virot et al. 2017). While the theoretical scaling of chewing rate to body mass is expected to be -0.25 , the empirical chewing rates have been found to vary mainly in the range -0.15 to -0.22 . The exponents observed thus seem to be systematically smaller, implying faster actual chewing than the theoretical scaling coefficient would suggest. Here we address this imparity.

We propose that the key to resolving this imparity lies in the adaptive relationships between dental morphology and mechanical properties of foods. Even though teeth scale isometrically with body mass (see, e.g., a review by Ungar 2014), the working surface of teeth may scale in different ways depending on their functional morphology. Mammalian molars often have linear structures formed of enamel crests, which work as the primary instruments for breaking food during mastication. Such structures are on the surface, but they are closer to linear than to surficial, and therefore do not necessarily scale directly with area. Therefore, if teeth primarily contain blades the working surface of teeth would be disproportionally smaller than the whole surface accommodating the blades, and the working surface would scale allometrically.

Regardless of dental morphology, animals need to process the amount of food expected from their body mass according to metabolic scaling. Teeth with a smaller working surface could, all else 
being equal, process the required amount of food by chewing it more times. This would explain why many empirical slopes of chewing rate scaling tend to suggest faster chewing than expected from overall tooth size.

\section{Scaling of teeth and chewing rate with metabolism}

The prevailing, if sometimes bitterly criticized, model for scaling ${ }^{1}$ of chewing rates (Fortelius 1985) relates chewing rates to metabolism in the following way.

The metabolic rate scales as $\mathrm{M}^{0.75}$ (Kleiber 1932). While empirically observed exponents vary to an extent from group to group and depending on how the basal metabolic rates are controlled, "it seems to be a very general rule that the minimal metabolic rates of related animals are about proportional to (body mass) ${ }^{3 / 4 "}$ (Alexander 1999). To satisfy this need the daily food intake must scale as $\mathrm{M}^{0.75}$. As far as is known, oral volume and bite size of food scale approximately as $\mathrm{M}^{1}$ (Clutton-Brock \& Harvey 1983, Pretorius et al. 2016). Larger animals have lower energy needs per unit of body mass. Yet with each bite they intake the amount of food that is proportional to their body mass. The metabolic requirements balance out via chewing, since larger animals chew more slowly (Fortelius 1985) and therefore process fewer mouthfuls per unit of feeding time. A constant chewing rate across all body sizes does not even seem to be feasible due to biophysical constraints (Virot et al. 2017).

Based on pilot data and logical reasoning, Fortelius (1985) suggested that chewing rates should scale as $\mathrm{M}^{-0.25}$. The argument is that since teeth scale as $\mathrm{M}^{1}$, and since food is 3-dimensional, the amount of food processed by each chew of ideal, isometric teeth of the same shape should also scale as $\mathrm{M}^{1}$, regardless of the original size of the individual food items ingested. The metabolic rate requirements per unit time of feeding are then satisfied as food processed per one chew multiplied by the chewing rate (the number of chews per time unit): $M^{-0.25} M^{1}=M^{0.75}$.

Although largely unnecessary for the present argument, the model described above also fits other core scaling observations. If one chew results in an isometric volume of isometric particles, the number of chews per mouthful of food has to be constant across sizes, thus it should scale as $\mathrm{M}^{0}$. Furthermore, the number of mouthfuls of food needed to satisfy daily energy need will scale as $M^{0.75}$, and thus the number of chews per day will scale as $M^{0.75} M^{0} / M^{1}=M^{-0.25}$. Since the number of chews per day and the chewing rate (speed) both scale as $\mathrm{M}^{-0.25}$, the amount of time spent on chewing per day must be constant: $\mathrm{M}^{-0.25} / \mathrm{M}^{-0.25}=\mathrm{M}^{0}$. This mechanism allows organisms to satisfy their metabolic needs within the 24 hours of a day, independently of their body size.

On a daily basis larger animals make fewer chews in relation to their body mass, but they live longer. The lifespan of mammals scales as $\mathrm{M}^{0.25}$ (Linstedt and Calder 1981). Since the number of

\footnotetext{
${ }^{1}$ Scaling relationships are typically modeled as exponential equations: $E=a M^{b}$, where $M$ is the body mass, $E$ is the variable of interest (e.g. metabolic rate), and $a$ and $b$ are the model coefficients. In the logarithmic form of the same equation $b$ is the slope and $a$ is the constant, the latter is often omitted from the discussion. If $b=1$ then scaling is isometric meaning that $E$ increases in proportion to $M$. If $b>1$ then scaling is positively allometric meaning that $E$ increases faster than $M$. If $b<1$ then scaling is negatively allometric meaning that $E$ increases slower than $M$, which is the case, for example, for the relation between metabolic rates and body mass. If $b=0$ then $E$ is constant for all $M$. Some authors adjust regression models phylogenetically (Felsenstein 1985); however, such an adjustment assumes that evolution of traits is random following the Brownian motion model, and overestimates the impact of origin of a trait over natural selection (Felsenstein 1985, Westoby et al. 1995). Assuming that the relationship between traits and the occurrence of individuals in the environment is active and rapid, we use the ordinary least squares for parameter estimation. The rate of evolutionary change is completely irrelevant for this argument.
} 
chews per day scales as $\mathrm{M}^{-0.25}$, the number of chews per lifetime turns out to be constant $M^{0.25} M^{-0.25}=M^{0}$. Therefore, while teeth increase in proportion to the body size, the number of chews over lifetime, in principle, does not. Even though food is 3-dimensional, the surface of teeth that contacts food is 2-dimensional, as observed by Gould (1975). Since one mouthful of food scales as $\mathrm{M}^{1}$ and the surface of teeth scales as $\mathrm{M}^{2 / 3}$, the food-tooth contact per one chew scales as $M^{1} / M^{2 / 3}=M^{1 / 3}$. This implies that the wear rate of teeth per one chew must scale as $M^{1 / 3}$. Since the volume of teeth scales as $M^{1}$, their height accordingly scales as $M^{1 / 3}$. As teeth wear in relation of their height, a tooth of height $M^{1 / 3}$ that wears at a rate $M^{1 / 3}$ will last for $M^{0}$ chews, just enough for the lifetime.

The question of how dental wear occurs during the interaction between dental tissues with each other and with particles in the food is also largely orthogonal to the main argument. Suffice it to say that, conditioned on diet, tooth wear is expected to be independent of body size. To the best of our knowledge, no evidence exists to suggest that those processes would depend systematically on body size.

\section{How dental functional morphology relates to the breakage properties of foods}

The scaling model theoretically explains why chewing rates are expected to scale as $\mathrm{M}^{-0.25}$. Now we can proceed with the question why empirically observed scaling of chewing rates tends to be different. A hint comes from Lucas (2004), who argued from the perspective of fracture theory that "the working surface areas of teeth that fracture and fragment food particles will be proportional to $M^{0.5 "}$ (p. 143). Importantly, Lucas makes a distinction between plastic and elastic fracture of foods. Plastic foods deform before cracking when force is applied. A simple example of plastic behavior would be chewing gum. Fully elastic foods instead respond to force instantaneously by cracking. A nut would be a simple example of elastic food. Lucas argues (p. 95) that only few plant or animal tissues display plastic deformation, although later (p. 163) he mentions that fruits become almost completely plastic at ripeness.

Lucas' argument for $\mathrm{M}^{0.5}$ scaling of the working surface of teeth is developed for elastic foods. Reasoning from the biomechanical perspective of how energy propagates through a crack, he concludes that cracking of larger particles requires allometrically less force. He further argues that in case of elastic food the breakage area of tooth-food particle contacts cannot increase at a faster rate than the scaling of bite forces, which he shows to scale as $\mathrm{M}^{0.5}$. Later in the book (p. 163) Lucas hints that for fully plastic food, at the opposite end of the idealized spectrum, the working surface should be isometric, which implies scaling of the working surface as $\mathrm{M}^{0.67}$.

In practice many foods may be neither fully plastic nor fully elastic, but somewhere in between. In such a case, it would be reasonable to expect the working surface of teeth to scale empirically between $\mathrm{M}^{0.67}$ and $\mathrm{M}^{0.5}$. Following the scaling model of Fortelius (1985) we argue that food particles need to be broken into the same size in relation to tooth size (and ultimately body size), no matter whether food is plastic, elastic or in between. Assuming that this is the case, Table 1 tabulates what would be the expected chewing rate to satisfy the metabolic need of $\mathrm{M}^{0.75}$ for different types of food. We can immediately see that the expected chewing rates from fully plastic to fully elastic food closely resemble empirical rates reported in the literature. Since, following Lucas' arguments, the working surface of teeth breaking elastic food would need to be smaller than breaking plastic food, all else being equal less food would be processed by one chew in case of elastic food. The compensation to satisfy the expected metabolic rate could come from chewing 
more times instead. Therefore, we expect that for more elastic food chewing rates will be faster. Table 1. Chewing rates needed to satisfy the metabolic rate of $\mathrm{M}^{0.75}$ at different scaling of working surfaces of teeth. The computation assumes that the volume of food captured between the teeth is the same but the amount processed depends on the morphology. The amount of food processed per chew would then scale as the working surface of the tooth times food height, which scales as $\mathrm{M}^{1 / 3}$. The expected chewing rate would then be the metabolic rate $\left(\mathrm{M}^{0.75}\right)$ divided by the amount of food processed per chew.

\begin{tabular}{llll}
\hline Type of food & $\begin{array}{l}\text { Working surface } \\
\text { of a tooth }\end{array}$ & $\begin{array}{l}\text { Food processed } \\
\text { per chew }\end{array}$ & $\begin{array}{l}\text { Expected } \\
\text { chewing rate }\end{array}$ \\
\hline Fully plastic & $\mathrm{M}^{0.67}$ & $\mathrm{M}^{1}$ & $\mathrm{M}^{-0.25}$ \\
& $\mathrm{M}^{0.6}$ & $\mathrm{M}^{0.93}$ & $\mathrm{M}^{-0.18}$ \\
& $\mathrm{M}^{0.55}$ & $\mathrm{M}^{0.88}$ & $\mathrm{M}^{-0.13}$ \\
Fully elastic & $\mathrm{M}^{0.5}$ & $\mathrm{M}^{0.83}$ & $\mathrm{M}^{-0.08}$ \\
\hline
\end{tabular}

\section{Functional dental morphology successfully predicts scaling of chewing rate}

Chewing different types of food requires different dental morphology. Animals chewing on grass tend to have flat and high crowned teeth, while animals chewing on leaves and other browse tend to have lophed teeth which are not necessarily high crowned. Lignified plant foods are elastic, as can be inferred for example from data in Bernays (1991), and are primarily fractured by blades (Lucas 2004, p. 120). As argued in the previous section, for most elastic food the working surface area should be the smallest in relation to the overall tooth size (Table 1).

More specifically, with lophed teeth the major food processing work is done by the blades. It is obvious upon inspection that this results in the working surface of a lophodont tooth being much smaller than the overall surface. The extra surface is needed to support the lophs, which actually do the cutting. Lophed teeth would accordingly have the smallest working area in relation to the tooth size, and would therefore have the fastest chewing rates. We empirically analyze the relationship between chewing rates and dental morphology using the chewing data from Gerstner and Gerstein (2008) complemented by functional crown type data using the scoring scheme from Zliobaite et al. (2016). The crown type scores are listed in Table S4 in the Appendix.

The dental trait scoring scheme captures durability of teeth and their functional properties according to a tradition of dental functional morphology reaching back to Cuvier and Aristotle (Fortelius 1990). We use three traits that describe teeth in terms of their functional properties: presence of acute lophs, obtuse lophs and occlusal topography (flat or non flat). Lack of lophs would generally indicate fruit eaters and omnivores (bunodont teeth), presence of obtuse lophs in combination with flat occlusal topography would indicate grazers (plagiolophodont teeth), while presence of lophs, especially acute lophs, and non-flat topography would indicate browsers or mixed feeders (lophodont teeth). We expect bunodonts to feed on the most plastic food (fruits), we expect grazers' food to be semi-elastic and browsers' food to be the most elastic. Therefore, we expect bunodonts to have their chewing rates the closest to the baseline $\mathrm{M}^{-0.25}$, and browsers to have the fastest chewing rates, close to the limit of $\mathrm{M}^{-0.16}$ suggested by Virot et al. (2017).

The wear of herbivore teeth is not only a matter of damage to an optimal shape, but more typically the process by which the functional shape is generated and maintained (Fortelius 1985b, Janis and Fortelius 1988). Even though the appearance of the occlusal surface may change substantially with wear (see e.g. Anders et al. 2011 for detailed discussion), the functionally critical aspects have been found to be surprisingly robust to such change until very late stages (Fortelius 1985a, Fortelius \& Solounias 2000, King et al. 2005). We do not, however, expect chewing rates to change 
in response to wear stage, because chewing rates are governed by biomechanical processes which are constrained by the body size (Virot et al. 2017). The variable that is more likely to change at the stage when teeth are heavily worn is the number of chews per mouthful (Chen 2009), or even more likely, the animal would swallow larger particle sizes (Mishellany-Dutour 2008) delegating more food processing work to the guts. Chewing rates as well as the length of chewing vary from individual to individual and in relation to food properties as well as circumstances and time available for chewing (Chen 2009), yet our goal is to analyze broad patterns at the species level.

We analyze four orders of large herbivores for which crown type scores are available: Artiodactyla, Perissodactyla, Proboscidea and Primates. The primarily insectivorous primates of less than $1 \mathrm{~kg}$ body weight (Fleagle 1988) are analyzed separately. They exhibit the same scaling relationship as the rest but transposed, with the same exponent but a higher constant. This leaves 72 species of large herbivorous mammals for the main analysis. The analysis excludes carnivorans, including omnivorous taxa such as bears, but includes omnivorous ungulates and primates as well as insectivorous primates, which share the same basic design of the chewing apparatus with herbivorous ungulates.

Figure 1 visualizes scaling of chewing cycle duration with body mass for different groups defined by functional morphology of teeth. The scaling results obtained by ordinary least squares $\mathrm{fit}^{2}$ are given in Table 2, converting all results to chewing rate. Summary statistics of the fits as well as alternative slopes obtained by reduced major axis fit are given in Tables S1-S3 and Figure S1 in the Appendix.

We can see from the table that, as expected, forms lacking lophs have the slowest chewing rates, forms with obtuse lophs and flat occlusal surfaces are in the middle, while lophed forms with a non-flat occlusal surface have the fastest chewing rates, presumably to compensate for underscaling of the working surface relative to the whole surface.

The focus is on how relationship between body size and chewing rates is affected by the dimensionality of occlusal geometry. Under our reasoning, each occlusal class is its own entity with it characteristic scaling. In reality, these classes differ in their body size ranges, so that comparisons of absolute chewing rates across classes have complicated interpretations affected by many factors not considered here. Even though the three main classes (bunodonts, plagiolophodonts and lophodonts) have different ranges and distribution of body masses, the regression lines cross at around $40 \mathrm{~kg}$ body mass, as plotted in Figure 2 , suggesting a baseline body mass at which absolute chewing rates of different occlusal geometry coincide. Of all the large herbivores in our analysis only about $1 / 3$ are below this body mass (the medium body mass is around $65 \mathrm{~kg}$ ), therefore, for medium and large sized animals lower working surface of teeth (lophodonts) relates to faster absolute chewing rates, which all else being equal would presumably compensate for the deficit of working surface.

\footnotetext{
2 Historically, empirical relationships between body mass and chewing rates have been analyzed using reduced major axis (RMA) and ordinary least squares (OLS) fits interchangeably. We use OLS as the primary model, since it is more justified when biologically asymmetric relationship is modelled (Smith 2009), such as the chewing rate being dependent on body mass. Complementary analysis using RMA is presented in the Appendix (Supplementary material).
} 
Table 2. Empirical scaling of chewing rates in groups of species by teeth morphology, ordinary least squares fit. Fit statistics can be found in Table S1 in the Appendix.

\begin{tabular}{lllllc|}
\hline Group & Lophs & $\begin{array}{l}\text { Occlusal } \\
\text { topography }\end{array}$ & Implied diet & Implied properties & $\begin{array}{l}\text { Empirical scaling } \\
\text { of chewing rates }\end{array}$ \\
\hline All large herbivores & Yes or no & Any & Any & Any & $\mathrm{M}^{-0.196}$ \\
All with lophs & Yes & Any & Grass or leaves & Elastic to semi-elastic & $\mathrm{M}^{-0.173}$ \\
\hline Bunodonts & No & Any & Fruits and similar & Plastic & $\mathbf{M}^{-0.246}$ \\
Plagiolophodonts and similar & Yes (obtuse) & Flat & Mostly grass & Semi-elastic & $\mathbf{M}^{-0.207}$ \\
Lophodonts and similar & Yes & Non-flat & Leaves and similar & Elastic & $\mathbf{M}^{-0.155}$ \\
\hline Small Primates & No & Non-flat & Insects & Plastic & $M^{-0.249}$ \\
\hline
\end{tabular}
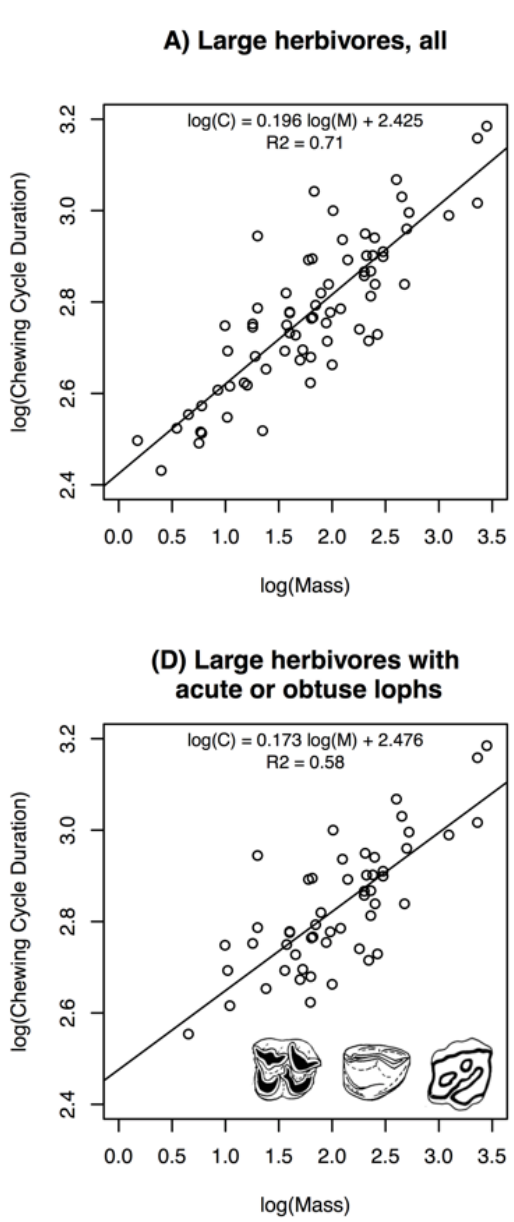

B) Large herbivores, no lophs (bunodonts)

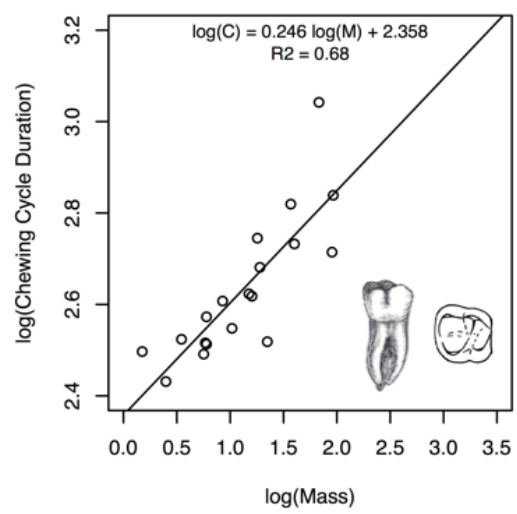

(E) Large herbivores with

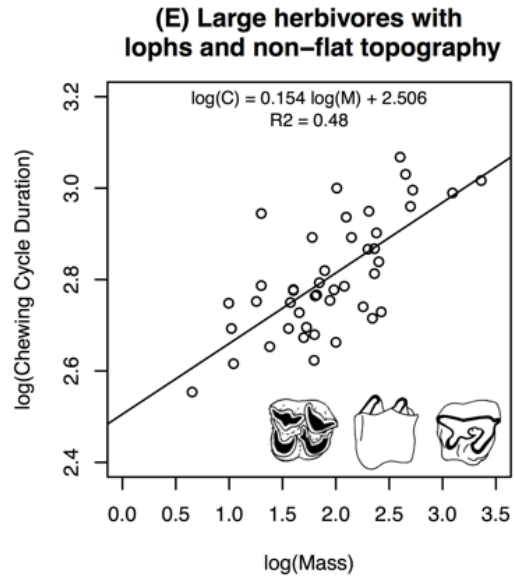

(C) Small Primates, no lophs

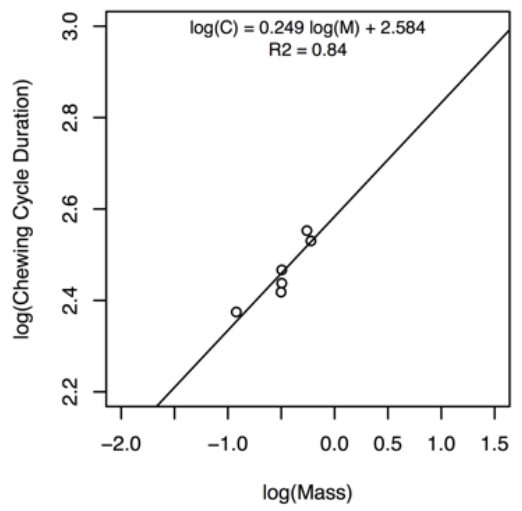

(F) Large herbivores with lophs and flat topography (grazers)

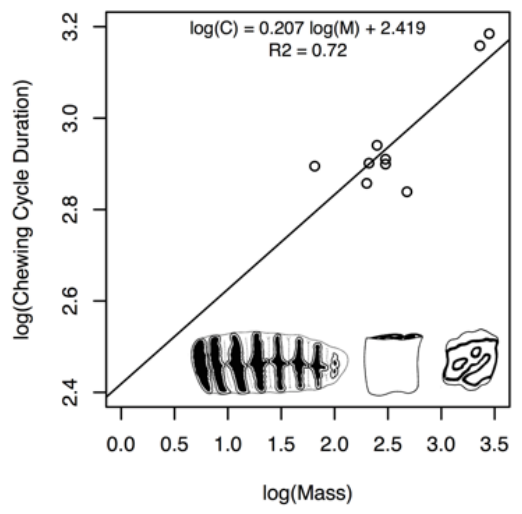

Figure 1. Scaling of chewing cycle duration with body mass, ordinary least squares fit. (A) Large herbivores (body mass more than $1 \mathrm{~kg}$ ) of orders Artiodactyla, Perissodactyla, Proboscidea and Primates with all dental crown types, the line indicates ordinary least squares fit, the regression equation and the coefficient of determination (R2) indicating model fit are given on the plot; (B) regression fit only on those large herbivores that have no lophs; (C) Small Primates (body mass less than $1 \mathrm{~kg}$ ), none have lophs; (D) regression fit only on those large herbivores that have lophs; (E) regression fit only on those large herbivores that have lophs and non-flat occlusal topography; (F) regression fit on those large herbivores that have lophs and flat occlusal topography. Tooth images are from Fortelius (1981), Thenius (1989) and public domain, tooth images are not to scale. 


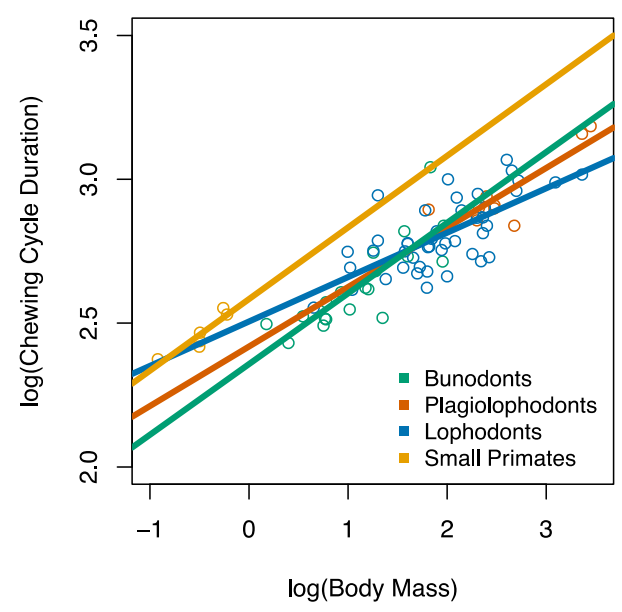

Figure 2. Intersection of regression line for different classes of occlusal geometry, ordinary least squares fit.

\section{Discussion and conclusion}

Our results explain the long-observed mismatch between theory and observed chewing rates. Lumping all herbivores, or all forms with lophs, gives allometric coefficients of the kind commonly reported in the literature, around or just below -0.2 (Fortelius 1985, Druzinsky 1993, Shipley et al. 1994, Gerstner and Gernstein 2008, Ross et al. 2009, Ungar 2014, Virot et al. 2017). When the species are sorted by occlusal morphology, corresponding to our argument about the relative size of the working surface, we observe the full spectrum from the theoretically expected -0.25 down to the lower limit of about -0.16 suggested by Virot et al. (2017). The theoretically predicted exponent of -0.25 is found in forms lacking lophs (bunodont herbivores and insectivorous primates), where the functional surface equals the entire occlusal surface.

There are in principle multiple ways in which the scaling of the functional occlusal surfaces could be adjusted to the metabolic needs. The surfaces themselves could for example be scaled up, the duration of chewing could be increased, or the chewing rate could be increased. To a first approximation it appears that the last of these is the predominant evolutionary solution. There is a certain amount of confusion about the role of dental size in functional evolution, arising from a general failure to make a distinction between the functional surface and the overall (basal) surface of teeth. Kay (1975a) actually came close to making that distinction when he observed that leafeating primates have larger molars for the same body size as compared to frugivorous primates (that do not have shearing crests on their molars) and that the scaling relationships depend on diet and morphology. Yet this line of reasoning appears to have been lost.

Substantially increasing the functional surface area would require correspondingly increased jaw size and muscle power (Turnbull 1970), while the increase in chewing duration could come up against ecological limits. Compared with these, increasing the rate of chewing appears easier, since it is known that animals are able to vary their chewing rate within certain physiological limits (Virot et al. 2017).

Our results suggest that the differences observed in chewing rates are explained by the breakage characteristics of different foods. Different kinds of foods that large mammals eat do indeed have different fracture characteristics, among which plasticity and elasticity are frequently mentioned. Plasticity is the property of a material to deform irreversibly, and elasticity is the property to deform reversibly. The conventional terms of functional dental research, such as cutting, shearing, grinding, crushing, represent attempts of researchers to capture their intuitive understanding of 
the principles of oral comminution. In principle, two kinds or processes are implied: either the food is compressed or it is partitioned. Here we have assumed a gradient from one to the other, roughly corresponding to the gradient from plastic to elastic.

Several authors, including Kay (1975b) and Fortelius (1986), have argued that the relationship between tooth size and body size cannot be fully understood without considering diet in the equation, but a physiological explanation and biomechanical context to do so has been largely lacking. Here we propose that the variability in chewing rates that is observed can be explained by considering how dental functional morphology has been tailored to different diets by functional adaptation. Different occlusal morphologies result in different ratios of the functional surface to the overall surface of teeth. When working surface does not scale with the overall surface of teeth and size of the animal, increased chewing rate appears to act as a compensation mechanism.

\section{Acknowledgements}

The authors acknowledge the ECHOES grant 274779 from the Academy of Finland. This is a contribution from the Valio Armas Korvenkontio Unit of Dental Anatomy in Relation to Evolutionary Theory.

\section{References}

Alexander, R. M. (1999). Energy for animal life. Oxford University Press.

Anders, U., von Koenigswald, W., Ruf, I. and Smith, H. B. (2010). Generalized individual dental age stages for fossil and extant placental mammals. Paläontologische Zeitschrift 85:321-339.

Bernays, E. (1991). Evolution of Insect Morphology in Relation to Plants. Philosophical Transactions: Biological Sciences 333 (1267), 257-264.

Chen, J. (2009). Food oral processing-A review. Food Hydrocolloids 23, 1-25.

Clutton-Brock, T. H. and Harvey, P. H. (1983). The functional significance of variation in body size among mammals. In J. F. Eisenberg and D. G. Kleiman (eds.): Advances in the Study of Mammalian Behavior. Special Pub. Amer. Soc. Mammal., 632-663.

Druzinsky, R. E. (1993). Time allometry of mammalian chewing movements, chewing frequency scales with body mass in mammals. Journal of Theoretical Biology 160, 427-440.

Felsenstein, J. (1985). Phylogenies and the Comparative Method. The American Naturalist 125 (1), 1-15.

Fleagle, J. G. (1988). Primate Adaptation and Evolution. Elsevier.

Fortelius, M. (1981). Functional aspects of occlusal cheek-tooth morphology in hypsodont non-ruminant ungulates in Proc. of International Symposium on Concept and Method in Palaeontology, Barcelona. pp. 153-162.

Fortelius, M. (1985a). The functional significance of wear-induced change in the occlusal morphology of herbivore cheek teeth, exemplified by Dicerorhinus etruscus upper molars. Acta Zool. Fennica 170: 157-158.

Fortelius, M. (1985). Ungulate cheek teeth: developmental, functional and evolutionary interrelations. Acta Zoologica Fennica 180:1-76.

Fortelius, M. (1986). Isometric scaling of mammalian cheek teeth is also true metabolic scaling. In Russell, D.E.; Santoro, J.-P.; Sigogneu-Russell, D. (eds.): Proceedings of the VIIth International Symposium on Dental Morphology, Paris 1986. Mémoires du Muséum national d'Histoire naturelle, Paris, Série C, 53:459-462. 
Fortelius, M. (1990). The mammalian dentition, a 'tangled' view. Netherlands Journal of Zoology 40 (1/2), p. 312-328.

Fortelius, M., and Solounias, N. (2000). Functional characterization of ungulate molars using the abrasion-attrition wear gradient: a new method for reconstructing paleodiets. American Museum Novitates, 1-36.

Gerstner, G. E. and Gerstein, J. B. (2008). Chewing rate allometry among mammals. Journal of Mammalogy 89, 10201030.

Gould, S. J. (1975). On the Scaling of Tooth Size in Mammals. American Zoologist 15 (2), 351-362.

Janis, C. M. and Fortelius, M., (1988). On the means whereby mammals achieve increased functional durability of their dentitions, with special reference to limiting factors. Biological Reviews (Cambridge) 63, 197-230.

Kay, R. F. (1975a). The functional adaptations of primate molar teeth. Am J Phys Anthropol. 43(2), 195-216.

Kay, R. F. (1975b). Allometry and early hominids -- comment. Science 189, 63-63.

King, S.J., Arrigo-Nelson, S.J., Pochron, S.T., Semprebon, G.M., Godfrey, L.R., Wright, P.C., Jernvall, J., 2005. Dental senescence in a long-lived primate links infant survival to rainfall. Proc. Natl. Acad. Sci. 102, 16579e16583.

Kleiber, M. (1932). Body size and metabolism. Hilgardia 6, 315-351.

Linstedt, S. L. and Calder, W. A. (1981). Body size, physiological time and longevity of homeometric animals. The Quarterly Review of Biology 56(1), p. 1-14.

Lucas, P. W. (2004). Dental Functional Morphology: How Teeth Work. Cambridge: Cambridge University Press.

Mishellany-Dutour, A., Renaud, J. Peyron, M. A., Rimek, F. and Woda, A. (2008). Is the goal of mastication reached in young dentates, aged dentates and aged denture wearers? British Journal of Nutrition 99(1):121-8

Pretorius, Y., de Boer, W. F., Kortekaas, K., van Wijngaarden, M., Grant, R. C., Kohi, E. M., Mwakiwa, E., Slotow, R., Prins, H. H. T. (2016). Why elephant have trunks and giraffe long tongues: how plants shape large herbivore mouth morphology. Acta Zoologica 97(2), p. 246-254.

Ross C. F., Washington R.L., Eckhardt A., Reed D.A., Vogel ER, Dominy N.J., Machanda Z.P. (2009). Ecological consequences of scaling of chew cycle duration and daily feeding time in Primates. Journal of Human Evolution 56(6):570-85.

Shipley, L. A., Gross, J. E., Spalinger, D. E., Hobbs, N. T. and Wunder, B. A. (1994). The Scaling of Intake Rate in Mammalian Herbivores. The American Naturalist 143 (6), 1055-1082.

Smith, R. J. (2009). Use and misuse of the reduced major axis for line-fitting. American Journal of Physical Anthropology 140(3):476-86.

Thenius, E. (1989). Zahne und gebiß der saugetiere in Handbook of Zoology, Mammalia, eds. Niethammer J, Schliemann H, Starck D. (Walter de Gruyter, Berlin) Vol. VIII, pp. 1-513.

Turnbull, W. D. (1970): Mammalian masticatory apparatus. Field Museum Press.

Ungar, P. (2014). Dental Allometry in Mammals: A Retrospective. Annales Zoologici Fennici 51(1-2):177-187.

Virot, E., Ma, G., Clanet, C. and Jung, S. (2017). Physics of chewing in terrestrial mammals. Scientific Reports 7, 43967.

Westoby, M., Leishman, M. R., Lord, J. M. (1995). On misinterpreting the 'phylogenetic correction'. Journal of Ecology 83(53), 1-534.

Zliobaite, I., Rinne, J., Toth, A., Mechenich, M., Liu, L., Behrensmeyer, A.K., Fortelius, M. (2016). Herbivore teeth predict climatic limits in Kenyan ecosystems. PNAS 113(45), 5 12751-12756. 


\section{Appendix}

Table S1 presents summary statistics for ordinary least squares fit. Tables S2 and S3, as well as Figure S1 present reduced major axis fit. Table $\mathrm{S} 4$ gives the dataset used for the analysis.

Table S1. Empirical scaling of chewing rates in groups of species by teeth morphology, ordinary least squares, summary statistics.

\begin{tabular}{|c|c|c|c|c|c|}
\hline Group & Slope & St. error for the slope & $\mathrm{Cl}$ 95\% for the slope & $R^{2}$ of the log-fit & Sample size \\
\hline All large herbivores & 0.196 & 0.015 & {$[0.166,0.226]$} & 0.71 & 72 \\
\hline All with lophs & 0.173 & 0.020 & {$[0.132,0.214]$} & 0.58 & 53 \\
\hline Bunodonts & 0.246 & 0.041 & {$[0.160,0.332]$} & 0.68 & 19 \\
\hline Plagiolophodonts and similar & 0.207 & 0.049 & {$[0.091,0.323]$} & 0.72 & 9 \\
\hline Lophodonts and similar & 0.155 & 0.024 & {$[0.105,0.204]$} & 0.48 & 44 \\
\hline Small Primates & 0.249 & 0.055 & {$[0.097,0.401]$} & 0.84 & 6 \\
\hline
\end{tabular}

Table S2. Empirical scaling of chewing rates in groups of species by teeth morphology, reduced major axis fit.

\begin{tabular}{lllllc|}
\hline Group & Lophs & $\begin{array}{l}\text { Occlusal } \\
\text { topography }\end{array}$ & Implied diet & Implied properties & $\begin{array}{c}\text { Empirical scaling } \\
\text { of chewing rates }\end{array}$ \\
\hline All large herbivores & Yes or no & Any & Any & Any & $\mathrm{M}^{-0.232}$ \\
All with lophs & Yes & Any & Grass or leaves & Elastic to semi-elastic & $\mathrm{M}^{-0.226}$ \\
Bunodonts & No & Any & Fruits and similar & Plastic & $\mathbf{M}^{-0.298}$ \\
Plagiolophodonts and similar & Yes (obtuse) & Flat & Mostly grass & Semi-elastic & $\mathbf{M}^{-0.244}$ \\
Lophodonts and similar & Yes & Non-flat & Leaves and similar & Elastic & $\mathbf{M}^{-0.222}$ \\
\hline Small Primates & No & Non-flat & Insects & Plastic & $\mathbf{M}^{-0.272}$ \\
\hline
\end{tabular}

Table S3. Empirical scaling of chewing rates in groups of species by teeth morphology, reduced major axis, summary statistics.

\begin{tabular}{lllll}
\hline Group & Slope & Cl 95\% for the slope & $\mathbf{R}^{2}$ of the log-fit & Sample size \\
\hline All large herbivores & 0.232 & {$[0.204,0.264]$} & 0.71 & 72 \\
All with lophs & 0.226 & {$[0.189,0.271]$} & 0.58 & 53 \\
Bunodonts & 0.298 & {$[0.224,0.396]$} & 0.68 & 19 \\
Plagiolophodonts and similar & 0.244 & {$[0.154,0.386]$} & 0.72 & 9 \\
Lophodonts and similar & 0.222 & {$[0.178,0.277]$} & 0.48 & 44 \\
Small Primates & 0.272 & {$[0.160,0.464]$} & 0.84 & 6 \\
\hline
\end{tabular}


A) Large herbivores, all

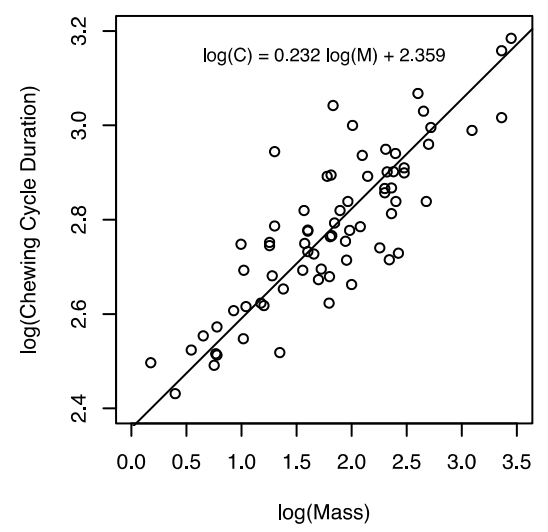

(D) Large herbivores with acute or obtuse lophs

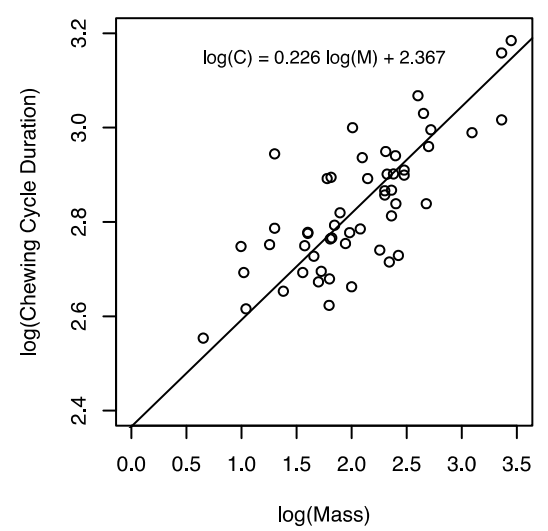

B) Large herbivores, no lophs (bunodonts)

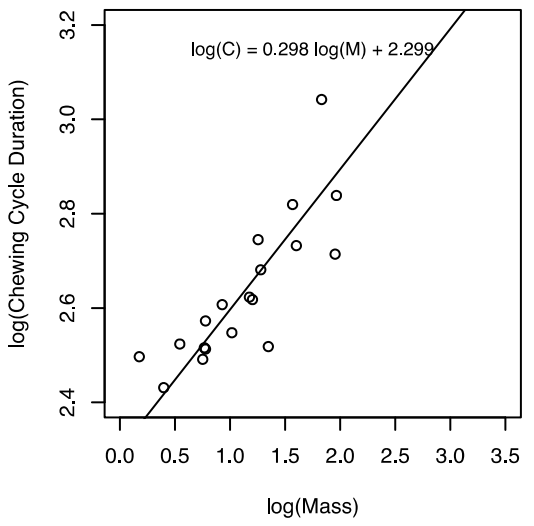

(E) Large herbivores with lophs and non-flat topography

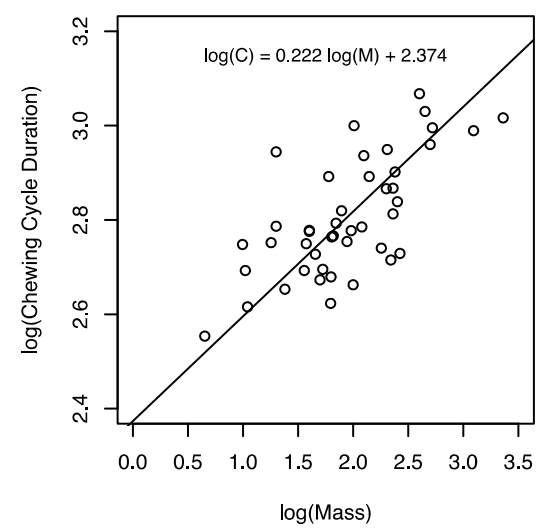

(C) Small Primates, no lophs

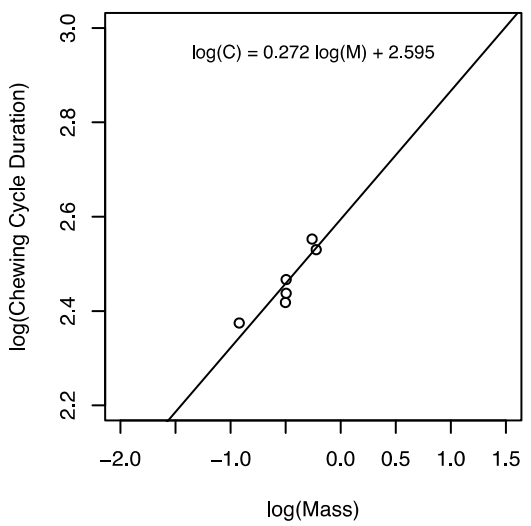

(F) Large herbivores with lophs and flat topography (grazers)

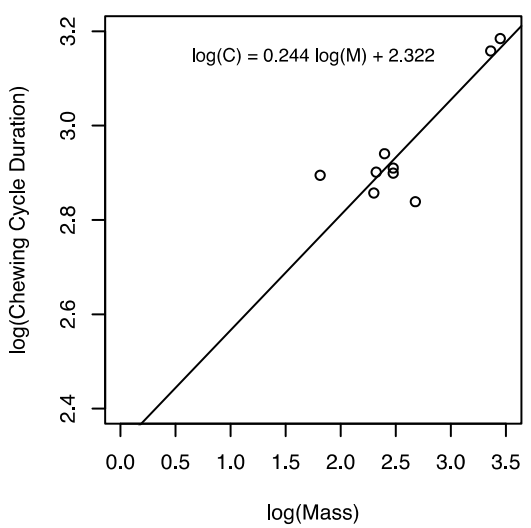

Figure S1. Scaling of chewing cycle duration with body mass, reduced major axis fit. (A) Large herbivores with all dental crown types, the line indicated reduced major axis fit; (B) regression fit only on those large herbivores that have no lophs; (C) Small Primates, none have lophs; (D) regression fit only on those large herbivores that have lophs; (E) regression fit only on those large herbivores that have lophs and non-flat occlusal topography; (F) regression fit on those large herbivores that have lophs and flat occlusal topography. 
Table S4. Data used in the analysis. Chewing rates and body mass are from Gerstner and Gerstein (2008), dental traits are from Zliobaite et al. (2016) and new data.

\begin{tabular}{|c|c|c|c|c|c|c|c|c|c|}
\hline Common name & Order & Family & Genus & Species & Mass (kg) & $\begin{array}{l}\text { Chewing cycle } \\
\text { duration (ms) }\end{array}$ & Acute lophs & Obtuse lophs & $\begin{array}{l}\text { Occlusal } \\
\text { topography }\end{array}$ \\
\hline Giraffe & Artiodactyla & Giraffidae & Giraffa & camelopardalis & 1240 & 976 & 0 & 1 & 0 \\
\hline Okapi & Artiodactyla & Giraffidae & Okapia & johnstoni & 240 & 798 & 0 & 1 & 0 \\
\hline European bison & Artiodactyla & Bovidae & Bison & bonasus & 300 & 793 & 0 & 1 & 1 \\
\hline Domestic cow & Artiodactyla & Bovidae & Bos & taurus & 476,272 & 690 & 0 & 1 & 1 \\
\hline Yak & Artiodactyla & Bovidae & Bos & grunniens & 250 & 872 & 0 & 1 & 1 \\
\hline Nilgai & Artiodactyla & Bovidae & Boselaphus & tragocamelus & 180 & 550 & 0 & 1 & 0 \\
\hline Sitatunga & Artiodactyla & Bovidae & Tragelaphus & spekii & 88 & 568 & 0 & 1 & 0 \\
\hline Nyala & Artiodactyla & Bovidae & Tragelaphus & angasii & 45,4 & 534 & 0 & 1 & 0 \\
\hline Greater kudu & Artiodactyla & Bovidae & Tragelaphus & strepsiceros & 252,5 & 690 & 0 & 1 & 0 \\
\hline Blackbuck & Artiodactyla & Bovidae & Antilope & cervicapra & 36 & 493 & 0 & 1 & 0 \\
\hline Dama gazelle & Artiodactyla & Bovidae & Nanger & dama & 63 & 478 & 0 & 1 & 0 \\
\hline Thomson's gazelle & Artiodactyla & Bovidae & Eudorcas & thomsonii & 24 & 450 & 0 & 1 & 0 \\
\hline Saudi goitered gazelle & Artiodactyla & Bovidae & Gazella & subgutturosa & 20 & 880 & 0 & 1 & 0 \\
\hline Springbok & Artiodactyla & Bovidae & Antidorcas & marsupialis & 37,5 & 562 & 0 & 1 & 0 \\
\hline Impala & Artiodactyla & Bovidae & Aepyceros & melampus & 62,5 & 420 & 0 & 1 & 0 \\
\hline Sable antelope & Artiodactyla & Bovidae & Hippotragus & niger & 230 & 737 & 0 & 1 & 0 \\
\hline Arabian oryx & Artiodactyla & Bovidae & Oryx & leucoryx & 70 & 621 & 0 & 1 & 0 \\
\hline Scimitar-horned oryx & Artiodactyla & Bovidae & Oryx & dammah & 204 & 890 & 0 & 1 & 0 \\
\hline Gemsbok & Artiodactyla & Bovidae & Oryx & gazella & 200 & 735 & 0 & 1 & 0 \\
\hline Addax & Artiodactyla & Bovidae & Addax & nasomaculatus & 102 & 1000 & 0 & 1 & 0 \\
\hline Rocky mountain goat & Artiodactyla & Bovidae & Oreamnos & americanus & 60 & 780 & 0 & 1 & 0 \\
\hline Dall's sheep & Artiodactyla & Bovidae & Ovis & dalli & 10,5 & 493 & 0 & 1 & 0 \\
\hline Himalayan tahr & Artiodactyla & Bovidae & Hemitragus & jemlahicus & 50 & 471 & 0 & 1 & 0 \\
\hline Alpine ibex & Artiodactyla & Bovidae & Capra & ibex & 40 & 597 & 0 & 1 & 0 \\
\hline Markhor & Artiodactyla & Bovidae & Capra & falconeri & 64 & 581 & 0 & 1 & 0 \\
\hline Goat & Artiodactyla & Bovidae & Capra & hircus & 40 & 600 & 0 & 1 & 0 \\
\hline Barbary sheep & Artiodactyla & Bovidae & Ammotragus & lervia & 66 & 584 & 0 & 1 & 0 \\
\hline Musk ox & Artiodactyla & Bovidae & Ovibos & moschatus & 400 & 1169 & 0 & 1 & 0 \\
\hline Waterbuck & Artiodactyla & Bovidae & Kobus & ellipsiprymnus & 220 & 519 & 0 & 1 & 0 \\
\hline Lechwe & Artiodactyla & Bovidae & Kobus & leche & 96 & 599 & 0 & 1 & 0 \\
\hline Blue duiker & Artiodactyla & Bovidae & Philantomba & monticola & 4,5 & 358 & 0 & 1 & 0 \\
\hline Elk & Artiodactyla & Cervidae & Cervus & elaphus & 266 & 536 & 0 & 1 & 0 \\
\hline Chital & Artiodactyla & Cervidae & Axis & axis & 53 & 496 & 0 & 1 & 0 \\
\hline Reeve's muntjac & Artiodactyla & Cervidae & Muntiacus & reevesi & 11 & 413 & 0 & 1 & 0 \\
\hline Indian muntjac deer & Artiodactyla & Cervidae & Muntiacus & muntjak & 18 & 565 & 0 & 1 & 0 \\
\hline Roe deer & Artiodactyla & Cervidae & Capreolus & capreolus & 20 & 612 & 0 & 1 & 0 \\
\hline Moose & Artiodactyla & Cervidae & Alces & alces & 450 & 1072 & 0 & 1 & 0 \\
\hline
\end{tabular}




\begin{tabular}{|c|c|c|c|c|c|c|c|c|c|}
\hline White-tailed deer & Artiodactyla & Cervidae & Odocoileus & virginianus & 78,5 & 660 & 0 & 1 & 0 \\
\hline Reindeer & Artiodactyla & Cervidae & Rangifer & tarandus & 125 & 864 & 0 & 1 & 0 \\
\hline Dromedary camel & Artiodactyla & Camelidae & Camelus & dromedarius & 525 & 990 & 0 & 1 & 0 \\
\hline Bactrian camel & Artiodactyla & Camelidae & Camelus & bactrianus & 500 & 912 & 0 & 1 & 0 \\
\hline Guanaco & Artiodactyla & Camelidae & Lama & guanicoe & 120 & 610 & 0 & 1 & 0 \\
\hline Llama & Artiodactyla & Camelidae & Lama & glama & 140 & 780 & 0 & 1 & 0 \\
\hline Alpaca & Artiodactyla & Camelidae & Lama & pacos & 100 & 460 & 0 & 1 & 0 \\
\hline Hippo & Artiodactyla & Hippopotamidae & Hippopotamus & amphibius & 2300 & 1039 & 0 & 1 & 0 \\
\hline Wild boar & Artiodactyla & Suidae & Sus & scrofa & 22,3 & 330 & 0 & 0 & 0 \\
\hline Warthog & Artiodactyla & Suidae & Phacochoerus & aethiopicus & 90 & 518 & 0 & 0 & 1 \\
\hline Collared peccary & Artiodactyla & Tayassuidae & Pecari & tajacu & 19 & 480 & 0 & 0 & 0 \\
\hline Brazilian tapir & Perissodactyla & Tapiridae & Tapirus & terrestris & 230 & 650 & 1 & 0 & 0 \\
\hline White rhinoceros & Perissodactyla & Rhinocerotidae & Ceratotherium & simum & 2300 & 1440 & 0 & 1 & 1 \\
\hline Grant's zebra & Perissodactyla & Equidae & Equus & burchellii & 200 & 720 & 0 & 1 & 1 \\
\hline Przewalski's horse & Perissodactyla & Equidae & Equus & przewalskii & 300 & 813 & 0 & 1 & 1 \\
\hline Domestic horse & Perissodactyla & Equidae & Equus & caballus & 65,0905 & 785 & 0 & 1 & 1 \\
\hline Asiatic wild ass & Perissodactyla & Equidae & Equus & hemionus & 210 & 797 & 0 & 1 & 1 \\
\hline African elephant & Proboscidea & Elephantidae & Loxodonta & africana & 2812,273 & 1530 & 0 & 1 & 1 \\
\hline Thick-tailed bush baby & Primates & Galagidae & Otolemur & crassicaudatus & 1,5 & 314 & 0 & 0 & 0 \\
\hline Ring-tailed lemur & Primates & Lemuridae & Lemur & catta & 2,5 & 270 & 0 & 0 & 0 \\
\hline Spider monkey & Primates & Atelidae & Ateles & geoffroyi & 6 & 326 & 0 & 0 & 0 \\
\hline Japanese macaque & Primates & Cercopithecidae & Macaca & fuscata & 15 & 420 & 0 & 0 & 0 \\
\hline Rhesus macaque & Primates & Cercopithecidae & Macaca & mulatta & 3,5 & 334 & 0 & 0 & 0 \\
\hline Mandrill & Primates & Cercopithecidae & Mandrillus & sphinx & 18 & 556 & 0 & 0 & 0 \\
\hline Sykes monkey & Primates & Cercopithecidae & Cercopithecus & mitis & 5,65 & 310 & 0 & 0 & 0 \\
\hline De Brazza's monkey & Primates & Cercopithecidae & Cercopithecus & neglectus & 5,85 & 328 & 0 & 0 & 0 \\
\hline Patas monkey & Primates & Cercopithecidae & Erythrocebus & patas & 8,5 & 405 & 0 & 0 & 0 \\
\hline Guereza & Primates & Cercopithecidae & Colobus & guereza & 9,9 & 560 & 1 & 0 & 0 \\
\hline Hanuman langur & Primates & Cercopithecidae & Semnopithecus & entellus & 16 & 415 & 0 & 0 & 0 \\
\hline White-handed gibbon & Primates & Hylobatidae & Hylobates & lar & 6 & 374 & 0 & 0 & 0 \\
\hline Siamang & Primates & Hylobatidae & Symphalangus & syndactylus & 10,4 & 353 & 0 & 0 & 0 \\
\hline Human & Primates & Hominidae & Homo & sapiens & 67,9 & 1102 & 0 & 0 & 0 \\
\hline Chimpanzee & Primates & Hominidae & Pan & troglodytes & 40 & 540 & 0 & 0 & 0 \\
\hline Gorilla & Primates & Hominidae & Gorilla & gorilla & 92,5 & 690 & 0 & 0 & 0 \\
\hline Orangutan & Primates & Hominidae & Pongo & pygmaeus & 37 & 660 & 0 & 0 & 0 \\
\hline
\end{tabular}

